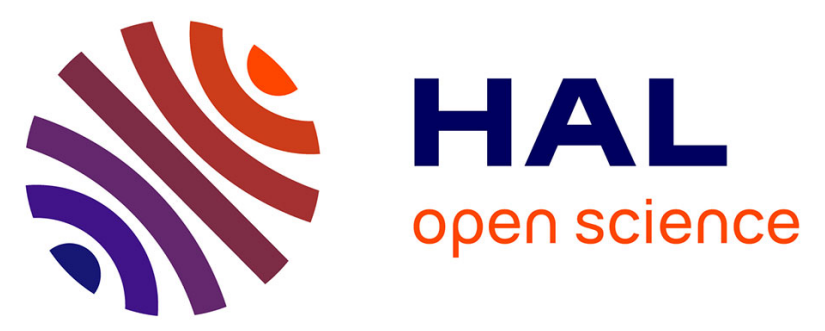

\title{
Combining RAIT and immune-based therapies to overcome resistance in cancer? Combining RAIT and immune-based therapies to overcome resistance in cancer?
}

Jean-Baptiste Gorin, Jérémie Ménager, Yannick Guilloux, Jean-François

Chatal, Joëlle Gaschet, Michel Cherel

\section{To cite this version:}

Jean-Baptiste Gorin, Jérémie Ménager, Yannick Guilloux, Jean-François Chatal, Joëlle Gaschet, et al.. Combining RAIT and immune-based therapies to overcome resistance in cancer? Combining RAIT and immune-based therapies to overcome resistance in cancer?. Resistance to Ibritumomab in Lymphoma, 18, pp 119-137, 2018, 10.1007/978-3-319-78238-6_9 . inserm-02338494

\section{HAL Id: inserm-02338494 https://www.hal.inserm.fr/inserm-02338494}

Submitted on 30 Oct 2019

HAL is a multi-disciplinary open access archive for the deposit and dissemination of scientific research documents, whether they are published or not. The documents may come from teaching and research institutions in France or abroad, or from public or private research centers.
L'archive ouverte pluridisciplinaire HAL, est destinée au dépôt et à la diffusion de documents scientifiques de niveau recherche, publiés ou non, émanant des établissements d'enseignement et de recherche français ou étrangers, des laboratoires publics ou privés. 


\section{Chapter 9}

\section{Combining RAIT and immune-based therapies to overcome resistance in cancer?}

Jean-Baptiste Gorin, CRCNA, UMR 892 Inserm, 6299 CNRS, Université de Nantes, 8 quai Moncousu, 44007 Nantes cedex 1, France.

Jérémie Ménager, CRCNA, UMR 892 Inserm, 6299 CNRS, Université de Nantes, 8 quai Moncousu, 44007 Nantes cedex 1, France.

Yannick Guilloux, UMR 892 Inserm, 6299 CNRS, Université de Nantes, 8 quai Moncousu, 44007 Nantes cedex 1, France.

Jean-François Chatal, GIP Arronax, 1 rue Aronnax, 44817 Saint-Herblain, France

Joëlle Gaschet, CRCNA, UMR 892 Inserm, 6299 CNRS, Université de Nantes, 8 quai Moncousu, 44007 Nantes cedex 1, France.

Michel Chérel, ICO-Gauducheau, CRCNA, UMR 892 Inserm, 6299 CNRS, Université de Nantes, 8 quai Moncousu, 44007 Nantes cedex 1, France.

\section{Acknowledgements}

This work has been supported by a grant from the French National Agency for Research titled "Investissements d'Avenir" Labex IRON (n ANR-11-LABX-0018-01), Labex IGO (n ANR11- LABX-0016-01) and ArronaxPlus Equipex (n॰ ANR-11-EQPX-0004), also by grants from La Ligue Contre le Cancer and from the Pays de la Loire Council "Nucléaire pour la Santé" (NucSan).

\section{Correspondence}

Joëlle Gaschet, CRCNA, UMR 892 Inserm, 6299 CNRS, Université de Nantes, 8 quai Moncousu, 44007 Nantes cedex 1, France. Email: Joelle.Gaschet@univ-nantes.fr

No conflict statement: No potential conflicts of interest were disclosed. 


\section{Abbreviations}

$\begin{array}{ll}\text { Ab } & \text { Antibody } \\ \text { ADCC } & \text { Antibody-Dependent Cellular Cytotoxicity } \\ \text { APC } & \text { Antigen Presenting Cells } \\ \text { CAR } & \text { Chimeric Antigen Receptor } \\ \text { CDC } & \text { Complement-Dependent Cytotoxicity } \\ \text { CEA } & \text { CarcinoEmbryonic Antigen } \\ \text { CpG } & \text { Cytosine-phosphate-Guanine motif } \\ \text { CR } & \text { Complete Response } \\ \text { CRT } & \text { Calreticulin } \\ \text { CRu } & \text { Unconfirmed Complete Response } \\ \text { DAMP } & \text { Damage-associated molecular pattern molecules } \\ \text { DC } & \text { Dendritic Cells } \\ \text { FIt3-L } & \text { Fms-related tyrosine kinase 3 - Ligand } \\ \text { G-CSF } & \text { Granulocyte-Colony Stimulating Factor } \\ \text { GM-CSF } & \text { Granulocyte-Macrophage Colony-Stimulating Factor } \\ \text { Gy } & \text { Gray } \\ \text { HMGB1 } & \text { High Mobility Group Box 1 } \\ \text { ICAM-1 } & \text { InterCellular Adhesion Molecule 1 } \\ \text { IFN } & \text { Interferon } \\ \text { IgG } & \text { Immunoglobulin G } \\ \text { IL } & \text { Interleukin } \\ \text { IU } & \text { International Unit } \\ \text { LFA-3 } & \text { Lymphocyte Function- Associated Antigen 3 } \\ \text { mAb } & \text { monoclonal Antibody } \\ \text { MHC } & \text { Major Histocompatibility Complex } \\ \text { MIP1 } \alpha & \text { Macrophage Inflammatory Protein 1 } \alpha \\ \text { MM } & \text { Multiple Myeloma } \\ \text { MTD } & \text { Maximum Tolerated Dose } \\ \text { NHL } & \text { Non-Hodgkin B-cell Lymphoma } \\ \text { NK } & \text { Natural Killer } \\ \text { NKG2D } & \text { Natural Killer Group 2D receptor } \\ \text { ORR } & \text { Overall Response Rate } \\ \text { PBMCs } & \text { Peripheral Blood Mononuclear Cells } \\ \text { PR } & \text { Partial Response } \\ \text { RAIT } & \text { Radioimmunotherapy } \\ \text { SD } & \text { Stable Disease } \\ \text { TAA } & \text { Tumor Associated Antigens } \\ \text { TLR } & \text { Toll Like Receptor } \\ \text { TNF } \alpha & \text { Tumor Necrosis Factor } \alpha \\ \text { VAM-1 } & \text { Vascular Cell Adhesion Molecule-1 } \\ & \end{array}$




\begin{abstract}
Radiation therapy has long been considered as immunosuppressive, therefore its impact on the immune system and other aspects which could be involved in raising efficient anti-tumor immune responses have been neglected. However the recent demonstration of the immunogenic properties of ionizing radiation is rapidely modifying the radiation oncology field and it also opens new and promising perspectives for the development and improvement of radioimmunotherapy. In this chapter, we first review the immunogenic properties of irradiation before discussing available evidence of the benefits of radiation therapy and immunotherapy combinations in the context of lymphoma.
\end{abstract}




\section{Introduction}

The use of ionizing radiation in cancer treatment armamentarium has become predominant as over half of the patients developing a tumor are now treated with irradiation during the course of their treatment [1,2]. Radioimmunotherapy (RAIT) remains a small fraction of such therapy despite the demonstration of its efficacy and safety in non-Hodgkin B-cell lymphoma (NHL) [3] and the promising results obtained in specific clinical settings of solid tumors $[4,5]$. For decades, research into improving RAIT have focused almost entirely on the approach itself, and significant progress have been made in humanization of monoclonal antibodies, development of new vectors, new radionuclides, more stable chelates, new delivery systems, better dosimetric models and definition of new target antigens. In parallel, radiobiological studies have addressed the direct and indirect (bystander) effects of ionizing radiation on the tumor cells to some extent, but for long, the complex interactions between the tumor, its microenvironment, inflammation and the immune system have been ignored by the field.

Among the established hallmarks of cancer are resistance to cell death, evading immune system, and creation of a tumor microenvironment [6]. Multiple immunosuppressive mechanisms are implemented by tumors to escape immune recognition and destruction which involve the tumor itself and its microenvironment [7]. For long, ionizing radiation and RAIT, often used in combination with chemotherapy, were also considered as immunosuppressive treatments. As a result, studies largely failed to appreciate the effects of ionizing radiation on immunity despite the fact that clinical cases of "abscopal effect" after radiotherapy were reported and that some patients achieved long term CR after a single dose of RAIT. The elucidation of the mechanisms underlying the off-target effects after irradiation and the demonstration that immunogenic tumor cell death is inducible by ionizing radiation have changed the perception of radiation therapy. And at a time where numerous and promising new immunotherapies are emerging, it also opens a new era of combination therapy options where the immunogenic effects of radionuclides could be a key factor for the success of treatment. 


\section{Ionizing Radiation and anti-tumor immunity}

\section{Abscopal effect: an aftermath of ionizing radiation involving the immune system}

The abscopal effect, originally described by Dr. RH. Mole in 1953 [8], comes from the latin "ab" meaning "far" and "scopos" which means "target ». The abscopal effect refers to effects outside the irradiation field of the target, which can result in anti-tumor responses and the elimination of non-irradiated tumor cells. More generally, abscopal effect stands for any systemic effect that is observed after a local treatment. A growing set of preclinical and clinical data point out that the therapeutic potential of ionizing radiation does not reflect only the antiproliferative and cytotoxic activities of $\mathrm{X}$ or $\mathrm{Y}$ radiation but also implies bystander and systemic (distant) effects [9-11].

This effect is rarely observed in the clinic, however, it has been documented in patients with hematological malignancies like lymphoma [12,13], leukemia [14,15], and also in patients with a wide variety of solid tumors [16-21]. Investigations of the possible mechanisms underlying the abscopal effect in animal models have demonstrated that it might be possible to favor the development of such event by modulating the immune system. Chakravarty et al. have shown in a syngeneic and immunocompetent metastatic lung cancer model that combining radiotherapy and injection of Flt3-Ligand (Flt3-L), a growth factor for immune cells and especially for dendritic cells (DC) [22], reduced lung metastases, significantly improved survival and resulted in $56 \%$ of disease free animals. Notably, the abscopal effect was abolished in nude mice lacking T-lymphocytes which demonstrates that this systemic anti-tumor effect is mediated by the adaptive immune system [23]. In a comparable study using a syngeneic immunocompetent breast carcinoma mouse model, Demaria et al. demonstrated that irradiation of a tumor implanted on the right flank combined with systemic injection of Flt3-L induced regression of a second tumor engrafted on the left flank of the animals. The combined treatment was ineffective if the second tumor was from another cell type than the irradiated breast carcinoma one or if the mice were deficient in Tcells [24]. So, in those studies, the abscopal effect was promoted by a tumor specific 
response relying upon T-lymphocytes. Another study, combining radiotherapy and injection of ECI301, a recombinant MIP1 $\alpha$ chemokine showed the involvement of $\mathrm{CD} 4^{+}$and $\mathrm{CD} 8^{+} \mathrm{T}^{-}$ cells or natural killer cells (NK) depending on the tumor type [25]. In addition, in this study, irradiation of healthy tissues did not promote any abscopal effect, which suggests that radiation-induced tumor cell death or damages are mandatory for the development of such anti-tumor response.

All these data indicate that ionizing radiation can initiate immune responses involving DC, NK and T-cells with systemic effects on tumor growth, highlighting the importance of the interactions between ionizing radiation and the immune system to foster an efficient antitumor response. It is therefore crucial to understand how irradiation acts on the tumor, its microenvironment and on the immune system.

\section{Immunological effects of ionizing radiation}

Cancer development is strongly influenced by inflammation, innate and adaptive immunity and the very complex interrelationships and modulations between those different components can either lead to tumor growth or to tumor regression. Although ionizing radiation has been mainly used to treat cancer through its direct cytotoxicity, there is now evidence that irradiation also modulates inflammation and the immune system at multiple levels including production of reactive oxydative species, generation of danger signals, release of cytokines and other soluble factors, activation of immune cells and induction of various type of cell death. Depending on the low or high dose of irradiation, the generation of acute or chronic inflammation, these underlying mechanisms can have immunosuppressive or immunostimulatory effects [26-30]. It is therefore important to understand the links between ionizing radiation and the immune response to cancer to try and develop treatments that could limit the immunosuppressive effects of radiation while boosting anti-tumor immunity. In the present chapter, we will focus on the studies that have shown the various mechanisms by which radiotherapy and chelated radionuclides might boost the immune system. 


\section{Modulation of tumor cell immunogenicity}

Although radiation therapy has been used traditionally to destroy tumor cells, the dose received by a number of cells within a given tumor mass, is too low to cause their destruction (event which is further emphasized in hypoxic areas). Several preclinical studies have shown however that such low radiation doses are capable of inducing phenotypic changes in neoplastic cells, which help their recognition and their destruction by the immune system. The molecules described to be up-regulated at the surface of tumor cells by such ionizing radiation doses are Tumor-associated antigen (TAA), MHC-Class I molecules, the death receptor Fas (CD95), NKG2D ligands, the costimulatory molecule B7-1 (CD80) and adhesion molecules including LFA-3 (CD58 or lymphocyte function-associated antigen 3) and ICAM-1 (Intercellular adhesion molecule 1) [31-37], Fas, MHC-Class I molecules, ICAM-1 and TAA such as CEA (Carcinoembryonic antigen) and the mucin glycosylated phosphoprotein Muc-1 have also been shown to be upregulated on tumor cells after irradiation with $\beta$ particle emitters ${ }^{153} \mathrm{Sm}$ [38] and ${ }^{90} \mathrm{Y}$ [39]. Interestingly, the B7-1 costimulatory molecule is also up-regulated in B-cell lymphoma following irradiation [40]. All these molecules are known to play a role in tumor destruction by cytotoxic $\mathrm{CD} 8^{+} \mathrm{T}$-cells and the development of an anti-tumor immune response.

One of the major consequences induced by tumor destruction after irradiation is the exposure of a large amount of TAA to the immune system. The delivery of tumor antigens is done because of tumor cell necrosis, apoptosis or the release cell fragments [41,42]. The increased availability of those TAA allows circulating DC to capture, present and then induce a specific T-cell response against the tumor. One study demonstrated that irradiated tumors expressing low levels of antigen, as MHC-peptide complex, provide a sufficient amount of TAA to allow the destruction of tumor cells by cytotoxic $C D 8^{+}$T cells [43].

Additionally, cell death induced by irradiation may allow the release of new TAA that will be captured by the DC in the tumor microenvironment and lymph nodes. Reits et al. have demonstrated that radiotherapy increases, within tumor cells, the repertoire of peptides available for MHC-Class I molecule presentation to cytotoxic CD8 ${ }^{+} \mathrm{T}$-cells. This broader repertoire does not only result from an increased degradation of the existing proteins, but 
also in activation of the mTOR pathway, which leads to increased protein translation and thus the creation of a new peptide repertoire [36].

\section{Immunogenic cell death}

All cell deaths do not promote an immune response. The immune system is able to distinguish between an immunogenic death and a non-immunogenic death which results either in the activation of adaptive immunity or in the persistence of tolerance. Tumor cell death induced by ionizing radiation can be quite immunogenic and potentiates the presentation of TAA by DC to activate T-cells and the development an immune response $[44,45]$. Several molecular danger signals, DAMP (Danger associated molecular pattern) have been identified among the main features of an immunogenic cell death.

1) The translocation of calreticulin (CRT), an endoplasmic reticulum chaperone protein, to the outer face of the plasma membrane of the cells undergoing apoptosis is an important "eat-me" signal for the professional antigen-presenting cells (APC) such as DC [46-49].

2) The release of HMGB1 (high mobility group box 1, a non-histone protein associated to chromatin and in the cell nucleus) by dying cells will transmit proinflammatory signals after binding to TLR4 (Toll-like receptor 4) [50-52]. Those DAMPs, CRT and/or HMGB1 are induced following exposure of tumors cells to external irradiation $[46,53]$ but also to $\alpha$-particle emitter like ${ }^{213} \mathrm{Bi}[54]$.

3) The third signal is the release of ATP from the cells undergoing apoptosis. ATP functions both as a "find-me" signal to professional APC and as a potent pro-inflammatory signal through binding to the $\mathrm{P} 2 \mathrm{X} 7$ purinergic receptor thereby triggering inflammasome activation [55-60]. Its release has not been demonstrated following irradiation yet. But, since autophagy is necessary for the release of ATP [61], and that ionizing radiation promotes autophagy [62-64], the third signal may be generated by ionizing radiation when autophagy precedes cell death. 
4) Heat-shock proteins, especially HSP70, are expressed at the cell surface but also released during tumor cell stress or cell death after exposure to ionizing radiation like X-rays $[65,66]$ or $\alpha$-particles [54], and stimulates innate and adaptive immune responses mediated by NK, DC cells and T-cells through antigen cross-presentation [67].

All these experimental data support that tumor cell stress and death resulting from ionizing radiation, are sensed by the immune system as "danger" signals which in turn can stimulate an immune response.

\section{Secretion of cytokines}

Radiotherapy also modifies tumor microenvironment by generating a proinflammatory environment $[29,68]$. For example, CXCL9, CXCL10 and CXCL16 chemokines promote the recruitment of $\mathrm{CD}^{+}$effector T-cells, and Th1 helper $\mathrm{CD} 4^{+} \mathrm{T}$-cells and are induced following ionizing radiation in various types of tumors [69-71]. Irradiation also promotes the production of proinflammatory cytokines such as IL-1 $\beta$, type I and type II IFN (IFN- $\alpha,-\beta,-\omega$ and IFN- $\gamma$ ) and TNFa, involved in the cytotoxic and cytostatic effects on cancer cells after irradiation, including tumor regression, inhibition of proliferation, tumor cell death and immune cell recruitment $[68,69,72-75]$. Such an inflammatory context after radiotherapy may facilitate the initiation and amplification of an anti-tumor immune response.

\section{Blood vessels}

After antigen activation, T-lymphocytes must reach and infiltrate tumors. Ionizing radiation can promote this process in many ways. For example, the radiation-induced remodeling of abnormal tumor vessels results in an effective tumor infiltration by anti-tumor T-cells following adoptive transfer in a transgenic mouse model of insulinoma [76]. In an experimental model of melanoma, increased expression of VCAM-1 adhesion molecule (Vascular cell adhesion molecule-1) induced by ionizing radiation boosts T-cell infiltration of the tumor [77]. 
Overall, these data demonstrate that ionizing radiation can drive an immune response to cancer in a number of ways, it is therefore important to consider these beneficial effects while designing cancer treatments. This also constitutes a strong rationale for combining radiation therapy with immunotherapy in order to improve current therapies. 


\section{Combining lonizing Radiation and Immunotherapy}

\section{Preclinical evidence in hematopoietic cancer models}

\section{Radiotherapy and immunotherapy}

By taking advantage of the immunogenic properties of ionizing radiation described in the previous sections, numerous preclinical studies have successfully combined radiotherapy with immunotherapies in solid tumors to obtain impressive responses (reviewed in [68],[78]). Here, we will focus on the available data for radiotherapy and immunotherapy combinations in preclinical models of lymphoma.

In 1997, the group of Batterman in Utrecht assessed the efficacy of supplementing local radiotherapy with locoregional low-dose injection of interleukin-2 (IL-2) in a subcutaneous model using the spontaneously arisen SL2 T-lymphoma $[79,80]$. IL-2 is a potent T cell activator, which has proved its efficacy and safety in the SL2 preclinical model $[81,82]$ as well as in human patients with Hodgkin's and non-Hodgkin's lymphoma [83-85]. In their SL2 model, they demonstrated that the combination of local radiation therapy (20Gy) followed by 2 cycles of 4-day injection of IL-2 (7000 IU/day) peri-tumorally led to 93\% of long-term disease-free survival compared to $17 \%$ with radiation alone $(p<0.0001)$. Additionally, in a setting where they inoculated mice with 2 subcutaneous tumors (one on each thigh), they showed that treatment of one tumor with irradiation and IL-2 led to anti-tumor effects in the second, untreated tumor in $80 \%$ of mice and local response was increased to $100 \%$. When the second, non-irradiated tumor was also treated with peritumoral IL-2, both local and distant responses increased to $100 \%$ and disease free survival reached $70 \%$. Interestingly, in an attempt to reproduce more closely the radiotherapy scheduled applied in clinic, they reproduced the experiments with a fractionated regimen of radiotherapy (2.5Gy/day for 10 days). Fractionated therapy was far less efficient than single dose regimen and led to only $12 \%$ local response and no disease-free survival. However, even in these settings, combination with IL-2 therapy improved treatment outcome up to $90 \%$ local response and $10 \%$ disease-free survival. The authors postulated that the selected 
fractionation schedule was not optimal for the SL2 model, possibly because it is a highly aggressive tumor that metastasizes quickly and therefore needs a rapid rather than prolonged treatment. They did not observe any toxicity related to IL-2 and therefore showed that IL-2 therapy was both safe and efficient in improving both local and systemic response to radiotherapy. This study was the first to demonstrate the potential of radiotherapeutic association with immunotherapy in a lymphoma model.

In 2003, the group of Illidge in Manchester tested the combination of total body irradiation with an agonistic anti-CD40 antibody on the murine $A 31$ and $\mathrm{BCL}_{1} \mathrm{~B}$-lymphoma models [86]. CD40 is a co-stimulatory protein expressed on APC such as DC, B-cells, monocytes and macrophages, and participates to their activation. Interestingly, CD40 is also expressed on various tumors, in particular B-cell lymphomas. Therapeutic treatment of lymphoma using agonistic antibodies targeted to CD40 can have multiple complementary anti-tumor effects. Indeed, activated APC are able to generate antigen-specific T-cell responses while the targeting of $\mathrm{CD}^{+} \mathrm{O}^{+}$tumor cells can have a direct tumoricidal effect by inducing apoptosis [87]. Interestingly, it has also been shown that anti-CD40 agonists can sensitize multiple myeloma (MM) and B-lymphoma cell lines to $\gamma$-radiation in vitro [88]. Anti-CD40 antibodies are the object of several ongoing clinical trials in leukemia, MM and NHL [89]. Recently, a phase II trial using an agonistic anti-CD40 as a monotherapy on patients with relapsed diffuse large B-cell lymphoma demonstrated low toxicity but only modest efficacy [90], suggesting that these therapies need combination with other cancer treatment modalities to reach their full potential. In this study, Honeychurch et al. showed that radiotherapy (5Gy) with anti-CD40 (1mg) led to an impressive long-term disease free survival of $100 \%$ of treated mice as opposed to $0 \%$ for single-agent treatments in both orthotropic models of lymphoma $\left(A 31\right.$ and $\left.B C L_{1}\right)$. Mice treated with a single treatment survived slightly longer than untreated controls but eventually all succumbed to their lymphoma. The effect of the combination treatment was not due to combined cytotoxicities as the anti-CD40 Ab did not induce cell death of lymphoma cell lines, nor did it sensitize the tumor cells to radiation. Instead the effect was mediated by a strong specific $\mathrm{CD}^{+} \mathrm{T}$-cell response which was long-lasting, as demonstrated by protection against later tumor challenge (therefore suggesting the onset of immune memory), and transferable to naive recipients. Interestingly, they observed that the combined therapy was less efficient on smaller tumor loads, indicating that radiation 
cytotoxicity needs to liberate a critical amount of TAA to allow anti-CD40 activated APCs to mount an efficient immune response. This study therefore brought to light mechanisms by which radiation therapy can synergize with immunotherapy by simultaneously reducing tumor load and providing antigens for an optimal immune response against lymphoma.

More recently, the same group published a study testing the association of local radiotherapy with the TLR7 agonist R848 in subcutaneous B-cell (A20) and T-cell (EL4, EG7) lymphoma models [91]. TLR7 is a pattern recognition receptor that is expressed on the endosomal membranes of DC (mainly plasmacytoid DC) and B-cells [92]. It has been shown to induce DC, B-cell and T-cell activation in vivo and lead to an effective anti-tumor cytotoxic T-cell response when combined with doxorubicin in a murine T-lymphoma model [93]. Studies also demonstrated that ex vivo stimulation of cutaneous T-cell lymphoma patients' PBMCs with TLR7 agonists induced the secretion of IFN- $\alpha$, IFN- $\gamma$ and led to NK cell and T-cell activation in vitro $[94,95]$. A phase II clinical trial also showed that treatment with the TLR7 agonist $825 \mathrm{~A}$ was well tolerated in patients with refractory hematological malignancies and associated with evidence of immune activation [96]. Finally, treatment with TLR7 agonists has also been shown to potentiate the efficacy of radiotherapy in preclinical models of solid tumors $[97,98]$. In their study, Dovedi et al. first demonstrated that systemic injection of R848 appeared well tolerated and led to increased levels of IL-6, IFN- $\gamma$, TNF- $\alpha$ and IL-5 and activation of B and T-lymphocytes in EG7 tumor-bearing mice. They then showed that the combination of local radiotherapy (10Gy) and intravenous injection of $\mathrm{R} 848(3 \mathrm{mg} / \mathrm{kg})$ could lead up to $75 \%$ of long term survival as compared to only $25 \%$ with either monotherapy. This improved outcome was not due to combined cytotoxicities as R848 did not sensitize EG7 tumor cells to radiation. Instead the effect was mediated by a specific $\mathrm{CD} 8^{+} \mathrm{T}$-cell response and led to the generation of long-lived specific memory T-cells. Depletion of B-cells with anti-CD20 Ab also showed that the efficacy of treatment combination in the T-lymphoma model was independent on B-lymphocytes. Interestingly, they showed that although radiotherapy alone induced the release of HMGB1 by tumor cells and led to their phagocytosis by DC, it was not sufficient to trigger DC activation. Addition of R848 was required to induce up regulation of $\mathrm{CD} 80$ and CD86 after irradiation of tumor cells, suggesting that both radiation and TLR7 stimulation were required to mount an efficient Tcell response. Finally they showed that using fractionated radiation regimen (5x2Gy) led to 
better responses in both EL4 T-lymphoma and A20 B-lymphoma models, leading to $100 \%$ of long-term survival. Interestingly, weekly injections of R848 for 5 weeks was more efficient than a single-dose, suggesting that repeated irradiation and immune stimulation could act as immune boosters for anti-tumor immunity and prevent the re-establishment of a suppressive tumor environment.

Although one could question the use of immune adjuvants in diseases originating from immune cells and hypothesize that stimulation with IL-2 in a T-cell malignancy could sustain tumor growth, or that CD40 and TLR agonists could promote B-lymphoma cell survival, those 3 studies demonstrate no such effect. On the contrary, the immunostimulants tested in these hematological malignancies all improve survival outcome with no apparent induced toxicity. These studies also clearly demonstrate that combining the immunogenic properties of ionizing radiation associated to tumor antigen release with immune stimulation can lead to efficient anti-tumor immunity. This immunity seems mainly driven by DC activation of specific cytotoxic $\mathrm{CD}^{+}$response, leading to the establishment of long-lasting immune memory. B cells do not seem to participate in the observed anti-tumor responses but other immune populations could potentially be involved and further investigations should address this possibility. Altogether, those findings warrant further trials of various immunemodulatory molecules and radiotherapy schedules in order to find the best combinations for the treatment of lymphomas.

\section{Radioimmunotherapy and immunotherapy}

To date, very few studies have investigated combination therapy of RAIT and immunotherapy in preclinical tumor models. To our knowledge, Chakraborty et al. have been the first to report such combination, in a study where RAIT was combined with cancer vaccination to treat human CEA expressing murine carcinoma in CEA transgenic mice [39]. This group had previously demonstrated that tumor cells were more susceptible to T-cell killing after exposure to non-lytic doses of external radiation therapy [34]. They thus hypothesized that delivering RAIT to a tumor mass might have the same effect. To this end, they used an ${ }^{90} \mathrm{Y}$-labeled anti-CEA mAb and a recombinant vaccine containing the CEA, B7-1, ICAM-1 and LFA-3 genes. They observed that survival of tumor engrafted mice was 
significantly increased after a single dose of RAIT in combination with vaccine compared to vaccine or radiolabeled mAb alone. Analysis of the immune response showed that in mice receiving the combination therapy, the amount of CEA-specific $\mathrm{CD}^{+}{ }^{+}$-cells infiltrating the tumor was significantly increased over vaccine alone. Interestingly, the animals cured after treatment with the combination therapy demonstrated a broadening in the anti-tumor immune response, since in addition to $\mathrm{CD}^{+}$and $\mathrm{CD} 8^{+}$T-cell responses against CEA which was encoded by the vaccine, they also observed T-cell responses against other TAA [39]. More recently, our group investigated the possibilities to promote an efficient and longlasting anti-tumor response by combining $\alpha$-RAIT and adoptive transfer of tumor specific Tlymphocytes in a multiple myeloma murine model expressing the TAA CD138 and ovalbumine (OVA) [99]. The therapeutic efficacy was evaluated by treatment with a ${ }^{213} \mathrm{Bi}-$ labeled anti-CD138, followed by an adoptive transfer of OT-I cells, which are OVA-specific $\mathrm{CD}^{+}$T-cells. We observed a significant tumor growth control and an improved survival in the animals treated with the combined treatment over radiolabeled mAb or OT-I cell transfer alone. Both studies demonstrate that not only radiotherapy by also RAIT in combination with immunotherapy promotes effective antitumor response, which may have implications in the design of future clinical trials.

\section{Clinical Evidence}

\section{Radiotherapy and immunotherapy}

The occurrence of abscopal effects after radiotherapy without concurrent immune stimulation is a rare event in the clinic. Although this may be due in part to underreporting, it is likely a consequence of tumor-derived immunosuppression and suggests that the threshold for anti-tumor immune activation is high in clinical settings. Notably, most of the reported cases of abscopal effect occurred in renal cell carcinoma, melanoma and lymphoma [100], indicating that these cancers are the most likely to benefit from combination with immunotherapy. Clinical trials have assessed the efficacy of various immunotherapies in combination with radiotherapy [101] and many trials are still ongoing [102] but most of the work has been performed on patients with solid non hematopoietic tumors, in particular melanoma [103]. 
The Stanford group is currently investigating the potency of combined treatments in patients with lymphoma in three trials testing the efficacy of radiotherapy associated with the TLR9 agonist SD-101 (NCT02266147, NCT01745354) and the anti-CTLA4 mAb Ipilimumab (NCT02254772). They also already published one study on the subject [104]. In this study, 15 patients with recurrent stage III or IV low grade B-cell lymphoma were treated with local radiotherapy combined with intra-tumoral TLR9 agonist (CPG PF-3512676) injection at one site only while distant tumor sites were evaluated for response. There was no treatment limiting adverse event and all patients completed the full course of therapy. They obtained $27 \%$ of overall objective response rate at the distant untreated sites with 1 CR lasting 61 weeks, 3 PR lasting 20, 64 and over 111 weeks and 8 SD. Tumor reactive CD $8^{+}$T-cells were detected in peripheral blood of several responding patients but no significant correlation between T-cell immunity and clinical response was found. Interestingly, some patients' tumor were able to induce a T-reg phenotype in autologous $\mathrm{CD}^{+}{ }^{+}$T-cells in vitro and those patients had significantly shorter progression free survival. This suggests that tumor-derived immunosuppression may be the main obstacle to treatment efficacy. These preliminary results warrant confirmation, nevertheless, this is the first study to demonstrate that association of radiotherapy with intratumoral injection of an immunostimulant can be safe and trigger efficient systemic responses in patients with lymphoma.

\section{Radioimmunotherapy and immunotherapy}

Only one trial tested the combination of RAIT with an immune stimulant so far [105] and the same team also recently completed a trial in which they tested the association of ${ }^{90} \mathrm{Y}$ ibritumomab tiuxetan with rituximab, G-CSF and IL-11 (NCT00012298) but the results have not been published at the time this manuscript was produced. In the former study, 30 patients with relapsed or refractory $\mathrm{CD}_{20} \mathrm{O}^{+} \mathrm{B}$-cell $\mathrm{NHL}$ have been treated with ${ }^{90} \mathrm{Y}$ ibritumomab tiuxetan $(0.4 \mathrm{mCi} / \mathrm{kg})$ in association with rituximab $(250 \mathrm{mg} / \mathrm{kg})$ and $\mathrm{CpG} 7909$, a TLR9 agonist. Four doses of CpG 7909 have been tested $(0.08,0.16,0.32$ and $0.48 \mathrm{mg} / \mathrm{kg}$ ) without reaching the MTD, demonstrating the safety of treatment. They obtained an impressive ORR of $93 \%$, with $63 \% \mathrm{CR} / \mathrm{CRu}$ and $30 \% \mathrm{PR}$, and responses were durable with a median time to progression of 42.7 months. T-cell responses have not been evaluated in this 
study but analysis of serum cytokines showed a statistically significant decrease in IL-10 and TNF $\alpha$ and increase in IL-1ß, consistent with the development of an immune response. It is important to note that IgG themselves can trigger immune responses. In particular, chimeric IgG such as rituximab have been shown to trigger $C D C$ and $A D C C$ in vitro. However the extent to which these phenomena participate in rituximab efficacy in vivo is still unclear [106]. In this trial, measurement of ADCC induced by rituximab was very variable between subjects and did not show any statistically significant difference between groups. Although they warrant confirmation, these phase I results are extremely encouraging. Nevertheless, further studies should assess the mechanisms and importance of the immune response in the efficacy of this treatment combination.

Based in part on the observations that $A b$ treatments could induce anti-tumor responses through the induction of $C D C, A D C C$ but also through Ab-targeted tumor antigen crosspresentation [107], it has been postulated that RAIT combined with maintenance anti-CD20 Ab treatment may trigger protective T-cell responses in lymphoma patients [108]. There has been several studies testing the efficacy of ${ }^{90} \mathrm{Y}$-ibritumomab tiuxetan after treatment with rituximab and chemotherapy [109-111] and all obtained very good response rate. However, only Jacobs et al. used rituximab as a maintenance treatment after RAIT and none of these trials assessed the presence of an anti-tumor immune response. Besides, chemotherapies used in those studies, such as fludarabine, cyclophosphamide and prednisone, can induce important immunosuppression and lymphopenia and may therefore limit the induction of an effective immune response against lymphoma.

Overall, results obtained from combination of RAIT and immune-related treatments in patients with lymphoma are very encouraging. However, there are still very little data available on the implication of the immune system in patient responses to these treatments. Notably, it will be of prime importance in the future to assess the effect of vectors on the immune response to tumors in RAIT. 


\section{Conclusions and perspectives}

Within the past two decades, important advances have been done in our knowledge of the complex interplay between ionizing radiation, inflammation and the immune system. The immunogenic properties of irradiation are now clearly demonstrated and, even though most of the data comes from external radation therapy, the few reports using radionuclides and RAIT strongly support that $\alpha$ - and $\beta$-particle emitters can also drive an anti-tumor immune response. More importantly, these immunogenic aspects have opened a new era of research in radiation oncology by the initiation of clinical trials combining ionizing radiation and immune-based therapy. Notably, preliminary results in patients with lymphoma are very encouraging. Combination therapies appeared safe and, to date, neither limiting adverse effects nor cumulative or overlapping toxicity were observed in any of the trials. These trials are initial investigations and there are still a lot of parameters to optimize in order to overcome tolerance and maximize the synergy of combined therapies towards tumor cell destruction. In that aspect RAIT may be of great interest in the treatment of disseminated and poor prognostic metastatic solid cancer as this approach will generate locally but at hundreds tumor sites: high dose to the tumor and cell death, production of ROS, release of TAA, acute inflammation and other immunogenic effects which should represent an ideal springboard for the combined immune-based therapy. In order to develop a systemic antitumor response, and to ultimately achieve an immune memory and long term protection, future directions will have to address which radionuclide, treatment schedule (single vs fractionation) and dose to use for different pathologies and different patients. Some clinical studies have already been completed but several more are about to start exploring radiation therapy in combination with immunotherapies using growth factors like Flt3-ligand or GMCSF [112] or checkpoint inhibitors such as anti-CTLA4 (Ipilumumab), anti-PD-1 (Nivolumab) [102] or anti-PD-L1 (Atezolizumab) mAbs. On july 2016, searching the clinicaltrials.gov website for checkpoint inhibitor mAb + radiation gives 41 results: 2 trials for Ipilumumab, 35 trials for Nivolumab , 4 trials for Atezolizumab. Among these 41 clinical trials, all but one use external radiation therapy, the remaining one will use ${ }^{90} \mathrm{Y}$ glass microspheres in hepatocellular carcinoma (NCT02837029). Despite the limited use of radionuclides so far, RAIT in combination with cytokines or immune checkpoints blocker do represent an exciting 
option. Several other attractive combination opportunities come from the development adoptive T-cell therapies and Chimeric Antigen Receptors (CAR) (for review $[113,114])$ and other class of small molecules designed for immuno-oncology treatment (for review [115]). This multitude of options implies to define biomarkers to identify patients who are the most likely to benefit from such combined treatment and especially from the immune-based therapy. 


\section{References}

1. Begg AC, Stewart FA, Vens C. Strategies to improve radiotherapy with targeted drugs. Nat Rev Cancer. 2011;11:239-53.

2. Delaney G, Jacob S, Featherstone C, Barton M. The role of radiotherapy in cancer treatment: estimating optimal utilization from a review of evidence-based clinical guidelines. Cancer. 2005;104:1129-37.

3. Tomblyn M. Radioimmunotherapy for B-cell non-hodgkin lymphomas. Cancer Control. 2012;19:196-203.

4. Kraeber-Bodéré F, Salaun P-Y, Oudoux A, Goldenberg DM, Chatal J-F, Barbet J. Pretargeted radioimmunotherapy in rapidly progressing, metastatic, medullary thyroid cancer. Cancer. 2010;116:1118-25.

5. Tomblyn MB, Katin MJ, Wallner PE. The new golden era for radioimmunotherapy: not just for lymphomas anymore. Cancer Control. 2013;20:60-71.

6. Hanahan D, Weinberg RA. Hallmarks of cancer: the next generation. Cell. 2011;144:64674.

7. Munn DH, Bronte V. Immune suppressive mechanisms in the tumor microenvironment. Current Opinion in Immunology. 2016;39:1-6.

8. Mole RH. Whole Body Irradiation-Radiobiology or Medicine? Br J Radiol. 1953;26:23441.

9. Mothersill C, Seymour CB. Radiation-induced bystander effects--implications for cancer. Nat Rev Cancer. 2004;4:158-64.

10. Prise KM, O'Sullivan JM. Radiation-induced bystander signalling in cancer therapy. Nat Rev Cancer. 2009;9:351-60.

11. Kroemer G, Zitvogel L. Abscopal but desirable: The contribution of immune responses to the efficacy of radiotherapy. Oncoimmunology. 2012;1:407-8.

12. Rees GJ. Abscopal regression in lymphoma: a mechanism in common with total body irradiation? Clin Radiol. 1981;32:475-80.

13. Antoniades J, Brady LW, Lightfoot DA. Lymphangiographic demonstration of the abscopal effect in patients with malignant lymphomas. Int. J. Radiat. Oncol. Biol. Phys. 1977;2:141-7.

14. Sham RL. The abscopal effect and chronic lymphocytic leukemia. Am. J. Med. 1995;98:307-8.

15. Aalbers AM, Aarts MJ, Krol ADG, Marijnen CAM, Posthuma EFM. The beneficial local and abscopal effect of splenic irradiation in frail patients with chronic lymphocytic leukaemia. Neth J Med. 2016;74:122-9. 
16. Stamell EF, Wolchok JD, Gnjatic S, Lee NY, Brownell I. The abscopal effect associated with a systemic anti-melanoma immune response. Int. J. Radiat. Oncol. Biol. Phys. 2013;85:293-5.

17. Grimaldi AM, Simeone E, Giannarelli D, Muto P, Falivene S, Borzillo V, et al. Abscopal effects of radiotherapy on advanced melanoma patients who progressed after ipilimumab immunotherapy. Oncoimmunology. 2014;3:e28780.

18. Cotter SE, Dunn GP, Collins KM, Sahni D, Zukotynski KA, Hansen JL, et al. Abscopal effect in a patient with metastatic Merkel cell carcinoma following radiation therapy: potential role of induced antitumor immunity. Arch Dermatol. 2011;147:870-2.

19. Ohba K, Omagari K, Nakamura T, Ikuno N, Saeki S, Matsuo I, et al. Abscopal regression of hepatocellular carcinoma after radiotherapy for bone metastasis. Gut. 1998;43:575-7.

20. Ishiyama H, Teh BS, Ren H, Chiang S, Tann A, Blanco Al, et al. Spontaneous regression of thoracic metastases while progression of brain metastases after stereotactic radiosurgery and stereotactic body radiotherapy for metastatic renal cell carcinoma: abscopal effect prevented by the blood-brain barrier? Clin Genitourin Cancer. 2012;10:196-8.

21. Takaya M, Niibe $Y$, Tsunoda S, Jobo T, Imai M, Kotani S, et al. Abscopal effect of radiation on toruliform para-aortic lymph node metastases of advanced uterine cervical carcinoma--a case report. Anticancer Res. 2007;27:499-503.

22. O'Neill DW, Adams S, Bhardwaj N. Manipulating dendritic cell biology for the active immunotherapy of cancer. Blood. 2004;104:2235-46.

23. Chakravarty PK, Alfieri A, Thomas EK, Beri V, Tanaka KE, Vikram B, et al. Flt3-ligand administration after radiation therapy prolongs survival in a murine model of metastatic lung cancer. Cancer Research. 1999;59:6028-32.

24. Demaria S, Ng B, Devitt ML, Babb JS, Kawashima N, Liebes L, et al. Ionizing radiation inhibition of distant untreated tumors (abscopal effect) is immune mediated. Int. J. Radiat. Oncol. Biol. Phys. 2004;58:862-70.

25. Shiraishi K, Ishiwata Y, Nakagawa K, Yokochi S, Taruki C, Akuta T, et al. Enhancement of antitumor radiation efficacy and consistent induction of the abscopal effect in mice by $\mathrm{ECl} 301$, an active variant of macrophage inflammatory protein-1alpha. Clin. Cancer Res. 2008;14:1159-66.

26. Formenti SC, Demaria S. Systemic effects of local radiotherapy. Lancet Oncol. 2009;10:718-26.

27. Golden EB, Formenti SC. Is tumor (R)ejection by the immune system the " 5 th $\mathrm{R}$ " of radiobiology? Oncoimmunology. 2014;3:e28133.

28. Frey B, Hehlgans S, Rödel F, Gaipl US. Modulation of inflammation by low and high doses of ionizing radiation: Implications for benign and malign diseases. Cancer Lett. 2015;368:230-7.

29. Lumniczky K, Safrany G. The impact of radiation therapy on the antitumor immunity: 
local effects and systemic consequences. Cancer Lett. 2015;356:114-25.

30. Hekim N, Cetin Z, Nikitaki Z, Cort A, Saygili El. Radiation triggering immune response and inflammation. Cancer Lett. 2015;368:156-63.

31. Ifeadi V, Garnett-Benson C. Sub-lethal irradiation of human colorectal tumor cells imparts enhanced and sustained susceptibility to multiple death receptor signaling pathways. PLoS ONE. 2012;7:e31762.

32. Kim J-Y, Son Y-O, Park S-W, Bae J-H, Chung JS, Kim HH, et al. Increase of NKG2D ligands and sensitivity to NK cell-mediated cytotoxicity of tumor cells by heat shock and ionizing radiation. Exp. Mol. Med. 2006;38:474-84.

33. Vondrácek J, Sheard MA, Krejcí P, Minksová K, Hofmanová J, Kozubík A. Modulation of death receptor-mediated apoptosis in differentiating human myeloid leukemia HL-60 cells. J. Leukoc. Biol. 2001;69:794-802.

34. Chakraborty M, Abrams SI, Camphausen K, Liu K, Scott T, Coleman CN, et al. Irradiation of tumor cells up-regulates Fas and enhances CTL lytic activity and CTL adoptive immunotherapy. J. Immunol. 2003;170:6338-47.

35. Garnett CT, Palena C, Chakraborty $M$, Chakarborty $M$, Tsang $K-Y$, Schlom J, et al. Sublethal irradiation of human tumor cells modulates phenotype resulting in enhanced killing by cytotoxic T lymphocytes. Cancer Research. 2004;64:7985-94.

36. Reits EA, Hodge JW, Herberts CA, Groothuis TA, Chakraborty M, Wansley EK, et al. Radiation modulates the peptide repertoire, enhances MHC class I expression, and induces successful antitumor immunotherapy. J. Exp. Med. 2006;203:1259-71.

37. Vereecque R, Buffenoir G, Gonzalez R, Cambier N, Hetuin D, Bauters F, et al. gamma-ray irradiation induces B7.1 expression in myeloid leukaemic cells. Br. J. Haematol. 2000;108:825-31.

38. Chakraborty M, Wansley EK, Carrasquillo JA, Yu S, Paik CH, Camphausen K, et al. The use of chelated radionuclide (samarium-153-ethylenediaminetetramethylenephosphonate) to modulate phenotype of tumor cells and enhance T cell-mediated killing. Clin. Cancer Res. 2008;14:4241-9.

39. Chakraborty M, Gelbard A, Carrasquillo JA, Yu S, Mamede M, Paik CH, et al. Use of radiolabeled monoclonal antibody to enhance vaccine-mediated antitumor effects. Cancer Immunol Immunother. 2008;57:1173-83.

40. Seo A, Ishikawa F, Nakano H, Nakazaki H, Kobayashi K, Kakiuchi T. Enhancement of B7-1 (CD80) expression on B-lymphoma cells by irradiation. Immunology. 1999;96:642-8.

41. Chen Z, Moyana T, Saxena A, Warrington R, Jia Z, Xiang J. Efficient antitumor immunity derived from maturation of dendritic cells that had phagocytosed apoptotic/necrotic tumor cells. Int. J. Cancer. 2001;93:539-48.

42. Kotera Y, Shimizu K, Mulé JJ. Comparative analysis of necrotic and apoptotic tumor cells 
as a source of antigen(s) in dendritic cell-based immunization. Cancer Research. 2001;61:8105-9.

43. Zhang M, Yao Z, Patel H, Garmestani K, Zhang Z, Talanov VS, et al. Effective therapy of murine models of human leukemia and lymphoma with radiolabeled anti-CD30 antibody, HeFi-1. Proc. Natl. Acad. Sci. U.S.A. 2007;104:8444-8.

44. Ma Y, Kepp O, Ghiringhelli F, Apetoh L, Aymeric L, Locher C, et al. Chemotherapy and radiotherapy: cryptic anticancer vaccines. Semin. Immunol. 2010;22:113-24.

45. Zitvogel L, Kepp O, Kroemer G. Decoding cell death signals in inflammation and immunity. Cell. 2010;140:798-804.

46. Obeid M, Tesniere A, Ghiringhelli F, Fimia GM, Apetoh L, Perfettini J-L, et al. Calreticulin exposure dictates the immunogenicity of cancer cell death. Nat. Med. 2007;13:54-61.

47. Panaretakis T, Kepp O, Brockmeier U, Tesniere A, Bjorklund A-C, Chapman DC, et al. Mechanisms of pre-apoptotic calreticulin exposure in immunogenic cell death. EMBO J. 2009;28:578-90.

48. Panaretakis T, Joza N, Modjtahedi N, Tesniere A, Vitale I, Durchschlag M, et al. The cotranslocation of ERp57 and calreticulin determines the immunogenicity of cell death. Cell Death Differ. 2008;15:1499-509.

49. Sukkurwala AQ, Martins I, Wang Y, Schlemmer F, Ruckenstuhl C, Durchschlag M, et al. Immunogenic calreticulin exposure occurs through a phylogenetically conserved stress pathway involving the chemokine CXCL8. Cell Death Differ. 2014;21:59-68.

50. Yamazaki T, Hannani D, Poirier-Colame V, Ladoire S, Locher C, Sistigu A, et al. Defective immunogenic cell death of HMGB1-deficient tumors: compensatory therapy with TLR4 agonists. Cell Death Differ. 2014;21:69-78.

51. Scaffidi P, Misteli T, Bianchi ME. Release of chromatin protein HMGB1 by necrotic cells triggers inflammation. Nature. 2002;418:191-5.

52. Tang D, Loze MT, Zeh HJ, Kang R. The redox protein HMGB1 regulates cell death and survival in cancer treatment. Autophagy. 2010;6:1181-3.

53. Apetoh L, Ghiringhelli F, Tesniere A, Obeid M, Ortiz C, Criollo A, et al. Toll-like receptor 4dependent contribution of the immune system to anticancer chemotherapy and radiotherapy. Nat. Med. 2007;13:1050-9.

54. Gorin J-B, Ménager J, Gouard S, Maurel C, Guilloux Y, Faivre-Chauvet A, et al. Antitumor immunity induced after $\alpha$ irradiation. Neoplasia. 2014;16:319-28.

55. Martins I, Tesniere A, Kepp O, Michaud M, Schlemmer F, Senovilla L, et al. Chemotherapy induces ATP release from tumor cells. cc. 2009;8:3723-8.

56. Elliott MR, Chekeni FB, Trampont PC, Lazarowski ER, Kadl A, Walk SF, et al. Nucleotides released by apoptotic cells act as a find-me signal to promote phagocytic clearance. Nature. 
$2009 ; 461: 282-6$.

57. Ghiringhelli F, Apetoh L, Tesniere A, Aymeric L, Ma Y, Ortiz C, et al. Activation of the NLRP3 inflammasome in dendritic cells induces IL-1beta-dependent adaptive immunity against tumors. Nat. Med. 2009;15:1170-8.

58. Aymeric L, Apetoh L, Ghiringhelli F, Tesniere A, Martins I, Kroemer G, et al. Tumor cell death and ATP release prime dendritic cells and efficient anticancer immunity. Cancer Research. 2010;70:855-8.

59. Martins I, Wang $Y$, Michaud $M$, Ma $Y$, Sukkurwala $A Q$, Shen $S$, et al. Molecular mechanisms of ATP secretion during immunogenic cell death. Cell Death Differ. 2014;21:7991.

60. Chekeni FB, Elliott MR, Sandilos JK, Walk SF, Kinchen JM, Lazarowski ER, et al. Pannexin 1 channels mediate "find-me" signal release and membrane permeability during apoptosis. Nature. 2010;467:863-7.

61. Michaud M, Martins I, Sukkurwala AQ, Adjemian S, Ma Y, Pellegatti P, et al. Autophagydependent anticancer immune responses induced by chemotherapeutic agents in mice. Science. 2011;334:1573-7.

62. Gorin J-B, Gouard S, Ménager J, Morgenstern A, Bruchertseifer F, Faivre-Chauvet A, et al. Alpha Particles Induce Autophagy in Multiple Myeloma Cells. Front Med (Lausanne). 2015;2:74.

63. Rieber M, Rieber MS. Sensitization to radiation-induced DNA damage accelerates loss of bcl-2 and increases apoptosis and autophagy. Cancer Biol. Ther. 2008;7:1561-6.

64. Rodriguez-Rocha H, Garcia-Garcia A, Panayiotidis MI, Franco R. DNA damage and autophagy. Mutat. Res. 2011;711:158-66.

65. Schildkopf P, Frey B, Ott OJ, Rubner Y, Multhoff G, Sauer R, et al. Radiation combined with hyperthermia induces HSP70-dependent maturation of dendritic cells and release of pro-inflammatory cytokines by dendritic cells and macrophages. Radiother Oncol. 2011;101:109-15.

66. Rubner Y, Muth C, Strnad A, Derer A, Sieber R, Buslei R, et al. Fractionated radiotherapy is the main stimulus for the induction of cell death and of Hsp70 release of p53 mutated glioblastoma cell lines. Radiat Oncol. 2014;9:89.

67. Multhoff G, Pockley AG, Schmid TE, Schilling D. The role of heat shock protein 70 (Hsp70) in radiation-induced immunomodulation. Cancer Lett. 2015;368:179-84.

68. Formenti SC, Demaria S. Combining radiotherapy and cancer immunotherapy: a paradigm shift. J. Natl. Cancer Inst. 2013;105:256-65.

69. Lugade AA, Sorensen EW, Gerber SA, Moran JP, Frelinger JG, Lord EM. Radiation-induced IFN-gamma production within the tumor microenvironment influences antitumor immunity. J. Immunol. 2008;180:3132-9. 
70. Matsumura S, Demaria S. Up-regulation of the pro-inflammatory chemokine CXCL16 is a common response of tumor cells to ionizing radiation. Radiat. Res. 2010;173:418-25.

71. Matsumura S, Wang B, Kawashima N, Braunstein S, Badura M, Cameron TO, et al. Radiation-induced CXCL16 release by breast cancer cells attracts effector $T$ cells. The Journal of Immunology. 2008;181:3099-107.

72. Ishihara H, Tsuneoka K, Dimchev AB, Shikita M. Induction of the expression of the interleukin-1 beta gene in mouse spleen by ionizing radiation. Radiat. Res. 1993;133:321-6.

73. Burnette BC, Liang $H$, Lee $Y$, Chlewicki L, Khodarev NN, Weichselbaum RR, et al. The efficacy of radiotherapy relies upon induction of type $i$ interferon-dependent innate and adaptive immunity. Cancer Research. 2011;71:2488-96.

74. Burnette B, Weichselbaum RR. Radiation as an immune modulator. Semin Radiat Oncol. 2013;23:273-80.

75. Ozsoy HZ, Sivasubramanian N, Wieder ED, Pedersen S, Mann DL. Oxidative stress promotes ligand-independent and enhanced ligand-dependent tumor necrosis factor receptor signaling. J. Biol. Chem. 2008;283:23419-28.

76. Ganss R, Ryschich E, Klar E, Arnold B, Hämmerling GJ. Combination of T-cell therapy and trigger of inflammation induces remodeling of the vasculature and tumor eradication. Cancer Research. 2002;62:1462-70.

77. Lugade AA, Moran JP, Gerber SA, Rose RC, Frelinger JG, Lord EM. Local radiation therapy of B16 melanoma tumors increases the generation of tumor antigen-specific effector cells that traffic to the tumor. J. Immunol. 2005;174:7516-23.

78. Reynders K, Illidge TM, Siva S, Chang JY, De Ruysscher D. The abscopal effect of local radiotherapy: using immunotherapy to make a rare event clinically relevant. Cancer Treat. Rev. 2015;41:503-10.

79. Everse LA, Renes IB, Jürgenliemk-Schulz IM, Rutgers DH, Bernsen MR, Dullens HF, et al. Local low-dose interleukin-2 induces systemic immunity when combined with radiotherapy of cancer. A pre-clinical study. Int. J. Cancer. 1997;72:1003-7.

80. Jürgenliemk-Schulz IM, Renes IB, Rutgers DH, Everse LA, Bernsen MR, Otter Den W, et al. Anti-tumor effects of local irradiation in combination with peritumoral administration of low doses of recombinant interleukin-2 (rIL-2). Radiat Oncol Investig. 1997;5:54-61.

81. Maas RA, Dullens HF, De Jong WH, Otter Den W. Immunotherapy of mice with a large burden of disseminated lymphoma with low-dose interleukin 2. Cancer Research. 1989;49:7037-40.

82. Masztalerz A, Everse LA, Otter WD. Presence of cytotoxic B220+CD3+CD4-CD8- cells correlates with the therapeutic efficacy of lymphoma treatment with IL-2 and/or IL-12. J. Immunother. 2004;27:107-15.

83. Poiré X, Kline J, Grinblatt D, Zimmerman T, Conner K, Muhs C, et al. Phase II study of 
immunomodulation with granulocyte-macrophage colony-stimulating factor, interleukin-2, and rituximab following autologous stem cell transplant in patients with relapsed or refractory lymphomas. Leuk. Lymphoma. 2010;51:1241-50.

84. Nagler A, Berger R, Ackerstein A, Czyz JA, Diez-Martin JL, Naparstek E, et al. A randomized controlled multicenter study comparing recombinant interleukin 2 (rIL-2) in conjunction with recombinant interferon alpha (IFN-alpha) versus no immunotherapy for patients with malignant lymphoma postautologous stem cell transplantation. J. Immunother. 2010;33:326-33.

85. Lum LG, Thakur A, Pray C, Kouttab N, Abedi M, Deol A, et al. Multiple infusions of CD20targeted T cells and low-dose IL-2 after SCT for high-risk non-Hodgkin's lymphoma: a pilot study. Bone Marrow Transplant. 2014;49:73-9.

86. Honeychurch J, Glennie MJ, Johnson PWM, Illidge TM. Anti-CD40 monoclonal antibody therapy in combination with irradiation results in a CD8 T-cell-dependent immunity to B-cell lymphoma. Blood. 2003;102:1449-57.

87. Khong A, Nelson DJ, Nowak AK, Lake RA, Robinson BWS. The use of agonistic anti-CD40 therapy in treatments for cancer. Int. Rev. Immunol. 2012;31:246-66.

88. Zhou Z-H, Shi Q, Wang J-F, Chen Y-J, Zhuang Y-M, Pan J-Z, et al. Sensitization of multiple myeloma and $B$ lymphoma lines to dexamethasone and gamma-radiation-induced apoptosis by CD40 activation. Apoptosis. 2005;10:123-34.

89. Hassan SB, Sørensen JF, Olsen BN, Pedersen AE. Anti-CD40-mediated cancer immunotherapy: an update of recent and ongoing clinical trials. Immunopharmacol Immunotoxicol. 2014;36:96-104.

90. de Vos S, Forero-Torres A, Ansell SM, Kahl B, Cheson BD, Bartlett NL, et al. A phase II study of dacetuzumab (SGN-40) in patients with relapsed diffuse large B-cell lymphoma (DLBCL) and correlative analyses of patient-specific factors. J Hematol Oncol. 2014;7:44.

91. Dovedi SJ, Melis MHM, Wilkinson RW, Adlard AL, Stratford IJ, Honeychurch J, et al. Systemic delivery of a TLR7 agonist in combination with radiation primes durable antitumor immune responses in mouse models of lymphoma. Blood. 2013;121:251-9.

92. Kobold S, Wiedemann G, Rothenfußer S, Endres S. Modes of action of TLR7 agonists in cancer therapy. Immunotherapy. 2014;6:1085-95.

93. Zhu J, He S, Du J, Wang Z, Li W, Chen X, et al. Local administration of a novel Toll-like receptor 7 agonist in combination with doxorubicin induces durable tumouricidal effects in a murine model of T cell lymphoma. J Hematol Oncol. 2015;8:21.

94. Wysocka M, Newton S, Benoit BM, Introcaso C, Hancock AS, Chehimi J, et al. Synthetic imidazoquinolines potently and broadly activate the cellular immune response of patients with cutaneous T-cell lymphoma: synergy with interferon-gamma enhances production of interleukin-12. Clin Lymphoma Myeloma Leuk. 2007;7:524-34. 
95. Wysocka M, Dawany N, Benoit B, Kossenkov AV, Troxel AB, Gelfand JM, et al. Synergistic enhancement of cellular immune responses by the novel Toll receptor $7 / 8$ agonist 3M-007 and interferon- $\gamma$ : implications for therapy of cutaneous T-cell lymphoma. Leuk. Lymphoma. 2011;52:1970-9.

96. Weigel BJ, Cooley S, DeFor T, Weisdorf DJ, Panoskaltsis-Mortari A, Chen W, et al. Prolonged subcutaneous administration of 852A, a novel systemic toll-like receptor 7 agonist, to activate innate immune responses in patients with advanced hematologic malignancies. Am. J. Hematol. 2012;87:953-6.

97. Dewan MZ, Vanpouille-Box C, Kawashima N, DiNapoli S, Babb JS, Formenti SC, et al. Synergy of topical toll-like receptor 7 agonist with radiation and low-dose cyclophosphamide in a mouse model of cutaneous breast cancer. Clin. Cancer Res. 2012;18:6668-78.

98. Adlard AL, Dovedi SJ, Telfer BA, Koga-Yamakawa E, Pollard C, Honeychurch J, et al. A novel systemically administered Toll-like receptor 7 agonist potentiates the effect of ionizing radiation in murine solid tumor models. Int. J. Cancer. 2014;135:820-9.

99. Ménager J, Gorin J-B, Maurel C, Drujont L, Gouard S, Louvet C, et al. Combining $\alpha$ Radioimmunotherapy and Adoptive T Cell Therapy to Potentiate Tumor Destruction. PLoS ONE. 2015;10:e0130249.

100. Abuodeh Y, Venkat P, Kim S. Systematic review of case reports on the abscopal effect. Curr Probl Cancer. 2016;40:25-37.

101. Seyedin SN, Schoenhals JE, Lee DA, Cortez MA, Wang X, Niknam S, et al. Strategies for combining immunotherapy with radiation for anticancer therapy. Immunotherapy. 2015;7:967-80.

102. Crittenden M, Kohrt H, Levy R, Jones J, Camphausen K, Dicker A, et al. Current Clinical Trials Testing Combinations of Immunotherapy and Radiation. Semin Radiat Oncol. 2015;25:54-64.

103. Barker CA, Postow MA. Combinations of radiation therapy and immunotherapy for melanoma: a review of clinical outcomes. Int. J. Radiat. Oncol. Biol. Phys. 2014;88:986-97.

104. Brody JD, Ai WZ, Czerwinski DK, Torchia JA, Levy M, Advani RH, et al. In situ vaccination with a TLR9 agonist induces systemic lymphoma regression: a phase I/II study. J. Clin. Oncol. 2010;28:4324-32.

105. Witzig TE, Wiseman GA, Maurer MJ, Habermann TM, Micallef INM, Nowakowski GS, et al. A phase I trial of immunostimulatory CpG 7909 oligodeoxynucleotide and 90 yttrium ibritumomab tiuxetan radioimmunotherapy for relapsed B-cell non-Hodgkin lymphoma. Am. J. Hematol. 2013;88:589-93.

106. Abulayha A, Bredan A, Enshasy El H, Daniels I. Rituximab: modes of action, remaining dispute and future perspective. Future Oncol. 2014;10:2481-92.

107. Weiner LM, Dhodapkar MV, Ferrone S. Monoclonal antibodies for cancer 
immunotherapy. Lancet. 2009;373:1033-40.

108. Buchegger F, Larson SM, Mach J-P, Chalandon Y, Dietrich P-Y, Cairoli A, et al. Radioimmunotherapy combined with maintenance anti-CD20 antibody may trigger longterm protective $T$ cell immunity in follicular lymphoma patients. Clin. Dev. Immunol. 2013;2013:875343.

109. Jacobs SA, Swerdlow SH, Kant J, Foon KA, Jankowitz R, Land SR, et al. Phase II trial of short-course CHOP-R followed by $90 \mathrm{Y}$-ibritumomab tiuxetan and extended rituximab in previously untreated follicular lymphoma. Clin. Cancer Res. 2008;14:7088-94.

110. Pisani F, Sciuto R, Dessanti ML, Giannarelli $D$, Kayal R, Rea S, et al. Long term efficacy and safety of Fludarabine, Cyclophosphamide and Rituximab regimen followed by (90)Yibritumomab tiuxetan consolidation for the treatment of relapsed grades 1 and 2 follicular lymphoma. Exp Hematol Oncol. 2015;4:17.

111. Witzig TE, Hong F, Micallef IN, Gascoyne RD, Dogan A, Wagner H, et al. A phase II trial of RCHOP followed by radioimmunotherapy for early stage (stages $\mathrm{I} / \mathrm{II}$ ) diffuse large B-cell nonHodgkin lymphoma: ECOG3402. Br. J. Haematol. 2015;170:679-86.

112. Golden EB, Chhabra A, Chachoua A, Adams S, Donach M, Fenton-Kerimian M, et al. Local radiotherapy and granulocyte-macrophage colony-stimulating factor to generate abscopal responses in patients with metastatic solid tumours: a proof-of-principle trial. Lancet Oncol. 2015;16:795-803.

113. Davila ML, Sadelain M. Biology and clinical application of CAR T cells for $B$ cell malignancies. Int. J. Hematol. 2016;104:6-17.

114. Morris EC, Stauss HJ. Optimizing T-cell receptor gene therapy for hematologic malignancies. Blood. 2016;127:3305-11.

115. Adams JL, Smothers J, Srinivasan R, Hoos A. Big opportunities for small molecules in immuno-oncology. Nat Rev Drug Discov. 2015;14:603-22. 